\title{
Association between body mass index and ready-to-eat food consumption among sedentary staff in Nay Pyi Taw union territory, Myanmar
}

Thin Zar Thike ${ }^{1,2}$, Yu Mon Saw ${ }^{2,3^{*}}$ D, Htin Lin ${ }^{1}$, Khin Chit ${ }^{1}$, Aung Ba Tun ${ }^{4}$, Hein Htet ${ }^{2,5}$, Su Myat Cho ${ }^{2}$, Aye Thazin Khine ${ }^{2,6}$, Thu Nandar Saw ${ }^{7}$, Tetsuyoshi Kariya ${ }^{2,3}$, Eiko Yamamoto ${ }^{2}$ and Nobuyuki Hamajima ${ }^{2}$

\begin{abstract}
Background: Ready-to-eat (RTE) food consumption has become popular in the working community with the increase in full-time jobs and the limited time to prepare food. Although RTE food is essential for this community, its consumption causes obesity. In Myanmar, obesity is a modifiable risk factor for non-communicable diseases, causing increases in morbidity and mortality. This study aimed to identify the association between body mass index (BMI) and RTE food consumption among sedentary staff in Nay Pyi Taw Union Territory, Myanmar.

Methods: A cross-sectional study was conducted in 2018, in which 400 respondents participated in face-to-face interviews. The study area was selected using simple random sampling and drawing method. Measuring tape and digital weighing scale were used to measure the height and weight of the respondents. BMI was calculated by dividing the weight by height squared $\left(\mathrm{kg} / \mathrm{m}^{2}\right)$. Overweight and obesity were categorized by World Health Organization cut-off points. The collected data were analyzed using multiple logistic regression to estimate the adjusted odds ratio (AOR), and the 95\% confidence interval (CI).

Results: This study revealed that sedentary staff who consumed RTE food once or more per month were nearly five times more likely to be overweight and obese (AOR $=4.78,95 \% \mathrm{Cl} 1.44-15.85)$ than those who consumed RTE food less frequently. In addition, five factors namely being older than 32 years ( $A O R=3.97,95 \% \mathrm{Cl} 1.82-8.69$ ), preference for RTE food ( $A O R=8.93,95 \% \mathrm{Cl} 2.54-31.37$ ), light-intensity of physical exercise ( $A O R=3.55,95 \% \mathrm{Cl}$ 1.63-7.73), sedentary leisure activities ( $\mathrm{AOR}=3.32,95 \% \mathrm{Cl} 1.22-9.03$ ), and smoking ( $\mathrm{AOR}=5.62,95 \% \mathrm{Cl} 1.06-29.90$ ) were positively associated with overweight and obesity.

Conclusion: Frequent consumers of RTE food and less physically active sedentary staff were more likely to be overweight and obese. This study highlights the urgent need to raise awareness regarding healthy lifestyle behaviors among the working community to reduce the burden of obesity-related chronic diseases. Moreover, sedentary workers should be aware of the food-based dietary guidelines of the country. Policy makers should strictly enforce nutritional labeling of RTE food, and strictly prohibit over-branding of RTE food.
\end{abstract}

Keywords: Ready-to-eat food, Sedentary staffs, Physical exercise, Nay Pyi Taw, Myanmar

\footnotetext{
* Correspondence: sawyumon@med.nagoya-u.ac.jp

${ }^{2}$ Department of Healthcare Administration, Nagoya University, Graduate

School of Medicine, 65 Tsurumai-cho, Showa-ku, Nagoya 466-8550, Japan

${ }^{3}$ Nagoya University Asian Satellite Campuses Institute, Nagoya, Japan

Full list of author information is available at the end of the article
}

(c) The Author(s). 2020 Open Access This article is distributed under the terms of the Creative Commons Attribution 4.0 International License (http://creativecommons.org/licenses/by/4.0/), which permits unrestricted use, distribution, and reproduction in any medium, provided you give appropriate credit to the original author(s) and the source, provide a link to the Creative Commons license, and indicate if changes were made. The Creative Commons Public Domain Dedication waiver (http://creativecommons.org/publicdomain/zero/1.0/) applies to the data made available in this article, unless otherwise stated. 


\section{Background}

The trend of ready-to-eat (RTE) food consumption has been increasing significantly globally due to rapid urbanization, busy lifestyles, and convenient access to fast food facilities [1, 2]. Due to their fast-paced lives, people prefer unhealthy RTE food to healthy homemade food, as it is affordable, readily accessible, and easy to prepare for everyone, especially for people in dualincome families [3-6]. Frequent and excessive RTE food consumption leads to obesity since it is high in calories, fats, and salts [7].

RTE food is defined as "a plant- or an animal-derived food that has to be frozen, cooked, and processed before it can be directly consumed and requires a very minimal time of preparation involving boiling or reheating before consumption" [8]. In the United States, 36\% of adults are reported to consume RTE food daily [9]. RTE food consumption has been increasing in Asia [10]. RTE food has an important part in high-income countries, as well as middle- and low-income countries, including Southeast Asia [11]. Unhealthy foods such as RTE food and a physically inactive lifestyle are not only the major risk factors for chronic non-communicable diseases (NCDs), but are also the main causes of obesity [12].

Obesity has an increasing trend and its prevalence has doubled worldwide since 1980 [13]. According to a global estimation study, more than 650 million people were estimated to have adult obesity and 1.9 billion people were estimated to be overweight in 2016 [14]. Overweight and obesity have become global public health problems and are some of the top leading causes of death [15]. World Health Organization (WHO) estimated that 4.5 million deaths worldwide were attributable to the consequences of overweight and obesity in 2016 [16]. Obese people are prone to have chronic diseases such as cardiovascular diseases, hypertension, and diabetes mellitus, leading to increased morbidity and mortality. Obesity-related chronic diseases are a burden for the country [17]. For example, 5 to $10 \%$ of the country expenditure is spent on obesity-related chronic diseases in the United States [18]. Diabetes mellitus, along with hypertension and physical inactivity, is still a major risk factor for cardiovascular diseases. The cost of treating these risk factors are far less than treating their consequences [19-22].

The rates of overweight and obesity have increased in developing countries [23], where the prevalence has increased from 857 million in 1980 to 2.1 trillion in 2013, which was equivalent to $60 \%$ of the global population [24]. In the Asia-Pacific region, the prevalence of overweight was 50\% in 2017 [25]. In Myanmar, the estimated prevalence of overweight increased from $24 \%$ in 2008 to $28 \%$ in 2015 , whereas the prevalence of obesity increased from $6 \%$ in 2008 to $13 \%$ in 2015 , implying an alarming rate of increase [26, 27]. In 2012, 59\% of total deaths occurred due to NCDs in Myanmar [28].

In Myanmar, RTE food consumption affects the country's economy. With the growing economic development, foreign investment in Myanmar has been expanding, especially in the food and beverages sector, an important component of the country's economy. Increasing demand for RTE food contributes to an increasing amount of imported food and beverages accounting for nearly $50 \%$ of the total import of the country. Local production of RTE food has been increasing as well. More than $60 \%$ of the family expenditure was being used for food [29, 30]. Along with economic, political, and social context changes, disease patterns have also been shifting from communicable to NCDs [31, 32]. Consumption of unhealthy food leads to obesity, one of the major risk factors for NCDs in Myanmar. Policy makers have targeted to promote healthy workplaces by reducing modifiable risk factors such as unhealthy diet, smoking, alcohol drinking, and sedentary activities [33, 34].

Most of the full-time staff working at a public institution in urban cities are sedentary, and their lifestyles cause them to consume RTE food. However, studies focusing on unhealthy diet consumption and physical activity status among sedentary workers are limited. This study aimed to identify the association between BMI and RTE food consumption among sedentary staff in Nay Pyi Taw Union Territory, Myanmar. This study is expected to support policymakers in implementing effective health promotion programs for reducing the prevalence of overweight and obesity among the working community, and for initiating healthy lifestyle behaviors at workplaces which, in turn, will reduce the burden of NCDs in the country.

\section{Methods \\ Study subjects}

A cross-sectional study was carried out at a public institution in Nay Pyi Taw Union Territory, Myanmar, from July to September 2018. Among the 25 public institutions in Nay Pyi Taw, one institution was selected by a drawing method first. Second, four departments from the institution were randomly selected by the same method. Third, 100 respondents aged between 18 and 60 years who attended the office on the study day were randomly recruited from the attendance list of the office to get the required sample. Pregnant women and lactating mothers were excluded from the survey. In total, 400 respondents participated in this study.

\section{Data collection}

Data were collected using pretested semi-structured questionnaires in Myanmar language. The research team 
included a leading researcher and three trained research assistants. The questionnaires included two main sections: 1) background characteristics and 2) RTE food consumption (Additional file 1). The height and weight of the respondents were measured by the trained research assistants, using a Seca measuring tape and a digital weighing scale, respectively. The weighing scale was calibrated before usage. Bodyweight was recorded to one decimal point. Standing body height was recorded to one decimal point with the respondents in barefoot. The respondents were informed about the study objectives and the content of the study prior to the interview. The respondents were interviewed face-to-face by the research team members. Each interview took about 30 to $40 \mathrm{~min}$ to complete, including the weight and height assessments.

\section{Statistical analysis}

The collected data were recoded and analyzed by using the Statistical Package for Social Science (SPSS) software version 21.0 (IBM SPSS Inc). To present the characteristic of the respondents, frequency distribution and percentage were used. BMI was calculated by dividing weight in kilogram by height in meter squared. It was categorized by using WHO cut-off points: BMI 25-29.9 $\mathrm{kg} / \mathrm{m}^{2}$ as overweight, and $\mathrm{BMI} \geq 30 \mathrm{~kg} / \mathrm{m}^{2}$ as obesity [35]. Chi-square test was used to compare categorical data. A multiple logistic regression analysis was used to estimate the adjusted odds ratio (AOR), and 95\% confidence interval $(\mathrm{CI})$. In this study, a $p$-value of less than 0.05 was considered as statistically significant.

\section{Results}

Table 1 presents the background characteristics of sedentary staff according to sex. Among the 400 respondents, $84.0 \%$ were female, and the rest were male. The mean age was 32 years and most of the respondents (54.8\%) were aged between 18 and 30 years at the time of the survey. Respondents working overtime for more than $5 \mathrm{~h}$ per month were $26.3 \%$. A majority of the respondents $(80.0 \%)$ were clerical and administrative staff, ranked below the gazetted officer level. Nearly one-third of the respondents were married, but $70.2 \%$ had no children. Among the respondents, $19.8 \%$ had a medical history of NCDs such as hypertension, diabetes mellitus, and ischemic heart diseases.

Table 2 shows the lifestyle characteristics of sedentary staff. Of 400 respondents, 3.5\% smoked, $6.8 \%$ consumed alcohol, and $49.5 \%$ had no habit of regular physical exercise. About half of the respondents (50.5\%) did regular physical exercise, but most of them (91.3\%) exercised less than 150 min per week. A majority (75.8\%) of the respondents performed sedentary leisure activities such as watching TV, surfing the internet, and reading, while
$12.7 \%$ used active transport such as going on foot or by bicycle. Regarding BMI, 14.2\% of respondents belonged to the overweight and obese category.

Table 3 shows RTE food consumption of sedentary staff. All respondents consumed RTE food, but the frequency of consumption was quite different. A majority of respondents (73.3\%) consumed RTE food more frequently. The most consumed types of RTE food were confections (91.3\%), instant-mixes (75.0\%), nonalcoholic beverages (59.8\%), and instant noodles (30.3\%). The vast majority of respondents $(84.0 \%)$ consumed RTE food for more than 1 year. Two-thirds of them (66.5\%) ate RTE food on their free time. Among them, 80.3\% had a habit of eating out for RTE food.

AOR and $95 \%$ CI of BMI $\geq 25 \mathrm{~kg} / \mathrm{m}^{2}$ among sedentary staff are shown in Table 4 . The respondents older than the mean age 32 years $(\mathrm{AOR}=3.97,95 \%$ CI 1.82-8.69) were four times more likely to be overweight and obese than younger ones. The sedentary staff consuming RTE food more than once in a month $(\mathrm{AOR}=4.78,95 \% \mathrm{CI}$ 1.44-15.58) were nearly five times more likely to be overweight and obese. Moreover, a positive association was found between overweight and obesity, and the preference for RTE food during their free time $(\mathrm{AOR}=8.93$, 95\% CI 2.54-31.37). Similarly, smokers (AOR $=5.62$, 95\% CI 1.06-29.90) were nearly six times more likely to be overweight and obese than non-smokers. Overweight and obesity (AOR $=3.55,95 \%$ CI $1.63-7.73$ ) were positively associated with light-intensity physical exercise, and sedentary leisure activity in leisure-time $(\mathrm{AOR}=3.32$, 95\% CI 1.22-9.03).

\section{Discussion}

To the best of our knowledge, this was the first study to identify the association between BMI and RTE food consumption among sedentary staff in Nay Pyi Taw Union Territory, Myanmar. It was found that frequent consumptions of RTE food were positively associated with overweight and obesity. In addition, the preference for eating RTE food during free time was nearly nine times more likely to contribute to overweight and obesity. In this study, respondents who were older, who did lightintensity physical exercise, who had sedentary leisure activities, and smokers were more likely to be overweight and obese than their counterparts.

In this study, the sedentary staff who consumed RTE food more than once per month were nearly five times more likely to be overweight and obese than those who did not. Sedentary staff mostly ate confections, carbonated beverages, instant noodles, and instant-mixes, which contained a large amount of calories, saturated fats, sugar, and salts. Food premises in public areas and canteens at workplaces facilitated workers to access RTE food easily. Respondents in this study were full-time 
Table 1 Background characteristics of sedentary staffs $(N=400)$

\begin{tabular}{|c|c|c|c|c|c|c|}
\hline \multirow[t]{2}{*}{ Characteristics } & \multicolumn{2}{|c|}{ Male $(n=64)$} & \multicolumn{2}{|c|}{ Female $(n=336)$} & \multicolumn{2}{|c|}{ Total $(N=400)$} \\
\hline & $n$ & $\%$ & $\mathrm{n}$ & $\%$ & $\mathrm{~N}$ & $\%$ \\
\hline \multicolumn{7}{|l|}{ Age (years) } \\
\hline $18-30$ & 31 & 48.4 & 188 & 56.0 & 219 & 54.8 \\
\hline $31-40$ & 14 & 21.9 & 108 & 32.1 & 122 & 30.5 \\
\hline $41-50$ & 13 & 20.3 & 28 & 8.3 & 41 & 10.2 \\
\hline $51-60$ & 6 & 9.4 & 12 & 3.6 & 18 & 4.5 \\
\hline \multicolumn{7}{|l|}{ Designation } \\
\hline Other rank & 41 & 64.1 & 279 & 83.0 & 320 & 80.0 \\
\hline Officer and above & 23 & 35.9 & 57 & 17.0 & 80 & 20.0 \\
\hline \multicolumn{7}{|l|}{ Average monthly overtime hour } \\
\hline Less than or equal to five & 40 & 62.5 & 255 & 75.9 & 295 & 73.7 \\
\hline More than five & 24 & 37.5 & 81 & 24.1 & 105 & 26.3 \\
\hline \multicolumn{7}{|l|}{ Marital status } \\
\hline Others $^{b}$ & 35 & 54.7 & 228 & 67.9 & 263 & 65.7 \\
\hline Married & 29 & 45.3 & 108 & 32.1 & 137 & 34.3 \\
\hline \multicolumn{7}{|l|}{ Presence of children } \\
\hline No & 38 & 59.4 & 243 & 72.3 & 281 & 70.2 \\
\hline Yes & 26 & 40.6 & 93 & 27.7 & 119 & 29.8 \\
\hline \multicolumn{7}{|l|}{ Number of children } \\
\hline Single & 47 & 73.4 & 301 & 89.6 & 348 & 87.0 \\
\hline More than one & 17 & 26.6 & 35 & 10.4 & 52 & 13.0 \\
\hline \multicolumn{7}{|l|}{ Type of family } \\
\hline Nuclear & 56 & 87.5 & 303 & 90.2 & 359 & 89.7 \\
\hline Extended & 8 & 12.5 & 33 & 9.8 & 41 & 10.3 \\
\hline \multicolumn{7}{|l|}{ Monthly family income $\left(\mathrm{MMK}^{\mathrm{C}}\right)$} \\
\hline Less than or equal to 450,000 & 38 & 59.4 & 239 & 71.1 & 277 & 69.2 \\
\hline More than 450,000 & 26 & 40.6 & 97 & 28.9 & 123 & 30.8 \\
\hline \multicolumn{7}{|l|}{ Presence of housemaid } \\
\hline Present & 4 & 6.3 & 7 & 2.1 & 11 & 2.8 \\
\hline Absent & 60 & 93.7 & 329 & 97.9 & 389 & 97.2 \\
\hline \multicolumn{7}{|l|}{ Role of cooking in family } \\
\hline Main & 9 & 14.1 & 185 & 55.1 & 194 & 48.5 \\
\hline Supportive & 55 & 85.9 & 151 & 44.9 & 206 & 51.5 \\
\hline \multicolumn{7}{|l|}{ Medical history of NCDs ${ }^{a}$} \\
\hline No & 47 & 73.4 & 274 & 81.5 & 321 & 80.2 \\
\hline Yes & 17 & 26.6 & 62 & 18.5 & 79 & 19.8 \\
\hline
\end{tabular}

${ }^{a}$ NCDs: non-communicable diseases (hypertension, diabetes mellitus and ischemic heart diseases)

bothers: single, divorced, separated, widow/widower, ${ }^{\circ}$ MMK-Myanmar kyats (1USD $=1512$ MMK on 22.4.2019)

workers working $8 \mathrm{~h}$ a day on weekdays. Sometimes, they had to work overtime on weekends. Thus, they did not spend much time in preparing home cooked meals. These factors caused them to consume RTE food more frequently than home-made meals. A study from the United States reported that frequent RTE food consumption led to increased energy intake, resulting in overweight and obesity [36]. This finding is in line with studies from Cameroon, Luxembourg, and Indonesia [37-39].

A similar finding was found in a Saudi study, which stated that frequent consumption of fast food was significantly associated with obesity [40]. Working people mainly consumed RTE food as they worked for long 
Table 2 Lifestyle characteristics of sedentary staffs ( $N=400)$

\begin{tabular}{|c|c|c|c|c|c|c|}
\hline \multirow[t]{2}{*}{ Characteristics } & \multicolumn{2}{|c|}{ Male $(n=64)$} & \multicolumn{2}{|c|}{ Female $(n=336)$} & \multicolumn{2}{|c|}{ Total $(N=400)$} \\
\hline & $n$ & $\%$ & $n$ & $\%$ & $\mathrm{~N}$ & $\%$ \\
\hline \multicolumn{7}{|l|}{ Smoking } \\
\hline No & 52 & 81.2 & 334 & 99.4 & 386 & 96.5 \\
\hline Yes & 12 & 18.8 & 2 & 0.6 & 14 & 3.5 \\
\hline \multicolumn{7}{|l|}{ Alcohol drinking } \\
\hline No & 44 & 68.7 & 329 & 97.9 & 373 & 93.2 \\
\hline Yes & 20 & 31.3 & 7 & 2.1 & 27 & 6.8 \\
\hline \multicolumn{7}{|l|}{ Habit of regular exercise } \\
\hline No & 27 & 42.2 & 171 & 50.9 & 198 & 49.5 \\
\hline Yes & 37 & 57.8 & 165 & 49.1 & 202 & 50.5 \\
\hline \multicolumn{7}{|c|}{ Average weekly physical exercise (in minutes) } \\
\hline More than or equal to150 & 10 & 15.6 & 25 & 7.4 & 35 & 8.7 \\
\hline Less than 150 & 54 & 84.4 & 311 & 92.6 & 365 & 91.3 \\
\hline \multicolumn{7}{|l|}{ Type of physical exercise } \\
\hline No and light intensity & 39 & 60.9 & 205 & 61.0 & 244 & 61.0 \\
\hline Moderate and high intensity & 25 & 39.1 & 131 & 39.0 & 156 & 39.0 \\
\hline \multicolumn{7}{|l|}{ Leisure activity } \\
\hline Non-sedentary & 12 & 18.7 & 85 & 25.3 & 97 & 24.2 \\
\hline Sedentary & 52 & 81.3 & 251 & 74.7 & 303 & 75.8 \\
\hline \multicolumn{7}{|l|}{ Travel with job } \\
\hline No & 19 & 29.7 & 133 & 39.6 & 152 & 38.0 \\
\hline Yes & 45 & 70.3 & 203 & 60.4 & 248 & 62.0 \\
\hline \multicolumn{7}{|c|}{ Distance between home and other places (in miles) } \\
\hline More than one & 20 & 31.3 & 130 & 38.7 & 150 & 37.5 \\
\hline Less than or equal to one & 44 & 68.7 & 206 & 61.3 & 250 & 62.5 \\
\hline \multicolumn{7}{|l|}{ Transportation facility } \\
\hline Others $^{b}$ & 57 & 89.1 & 292 & 86.9 & 349 & 87.3 \\
\hline On foot/bicycle & 7 & 10.9 & 44 & 13.1 & 51 & 12.7 \\
\hline \multicolumn{7}{|l|}{${ }^{a}$ BMI $\left(k g / m^{2}\right)$} \\
\hline$<25$ & 54 & 84.4 & 289 & 86.0 & 343 & 85.8 \\
\hline $25-29.9$ & 9 & 14.1 & 37 & 11.0 & 46 & 11.5 \\
\hline$\geq 30$ & 1 & 1.6 & 10 & 3.0 & 11 & 2.7 \\
\hline
\end{tabular}

${ }^{\mathrm{a} B M I}$ body mass index;

b Others: motorbike, car, and public transport

hours [41]. One study stated that full-time workers consumed fast food frequently due to convenience and tight working schedules, which led to obesity [42]. Therefore, the findings from this study suggest that awarenessraising campaigns on healthy dietary habits are urgently needed to be implemented in workplace settings. Regulatory authorities should strictly regulate food safety and food labeling. People should be aware of the nutritional contents of the food they consume.

This study also proved that the preference for RTE food consumption during free time was positively associated with overweight and obesity. In this study,
$70 \%$ of respondents stored RTE food in their residences. This storage practice favors free time consumption of RTE food. Moreover, in this study, sedentary staff usually ate out at cafeteria for fun during their free time. They had easy access to fast food facilities in urban cities. Increased RTE food advertisements in mass media is one of the key factors for consuming RTE food [43]. This finding was supported by a study in the United States which reported that working women preferred RTE food due to limited time [44]. In addition, one study showed that people consumed RTE food because of its taste, ease of 
Table 3 Ready-to-eat food consumption of sedentary staffs ( $N=400$ )

\begin{tabular}{|c|c|c|c|c|c|c|}
\hline \multirow[t]{2}{*}{ Characteristics } & \multicolumn{2}{|c|}{ Male $(n=64)$} & \multicolumn{2}{|c|}{ Female $(n=336)$} & \multicolumn{2}{|c|}{ Total $(N=400)$} \\
\hline & $n$ & $\%$ & $n$ & $\%$ & $\mathrm{~N}$ & $\%$ \\
\hline \multicolumn{7}{|l|}{ Frequency of RTE* food consumption } \\
\hline Less frequently consumed ${ }^{*}$ & 20 & 31.2 & 87 & 25.9 & 107 & 26.7 \\
\hline More frequently consumed ${ }^{\#}$ & 44 & 68.8 & 249 & 74.1 & 293 & 73.3 \\
\hline \multicolumn{7}{|l|}{ Instant noodle consumption } \\
\hline Less frequently consumed ${ }^{*}$ & 44 & 68.8 & 235 & 69.9 & 279 & 69.7 \\
\hline More frequently consumed ${ }^{\#}$ & 20 & 31.2 & 101 & 30.1 & 121 & 30.3 \\
\hline \multicolumn{7}{|l|}{ Sweet confectionaries consumption } \\
\hline Less frequently consumed ${ }^{*}$ & 9 & 14.1 & 26 & 7.7 & 35 & 8.7 \\
\hline More frequently consumed ${ }^{\#}$ & 55 & 85.9 & 310 & 92.3 & 365 & 91.3 \\
\hline \multicolumn{7}{|l|}{ Non-alcoholic beverages consumption } \\
\hline Less frequently consumed* & 22 & 34.4 & 139 & 41.4 & 161 & 40.2 \\
\hline More frequently consumed ${ }^{\#}$ & 42 & 65.6 & 197 & 58.6 & 239 & 59.8 \\
\hline \multicolumn{7}{|l|}{ Instant -mix consumption } \\
\hline Less frequently consumed ${ }^{*}$ & 11 & 17.2 & 89 & 26.5 & 100 & 25.0 \\
\hline More frequently consumed ${ }^{\#}$ & 53 & 82.8 & 247 & 73.5 & 300 & 75.0 \\
\hline \multicolumn{7}{|l|}{ Habit of eating out } \\
\hline Not eat out & 9 & 14.1 & 70 & 20.8 & 79 & 19.7 \\
\hline Eat out & 55 & 85.9 & 266 & 79.2 & 321 & 80.3 \\
\hline \multicolumn{7}{|l|}{ Reason of eating out } \\
\hline Fun/pleasure & 28 & 43.8 & 178 & 53.0 & 206 & 51.5 \\
\hline Change/time consuming & 36 & 56.2 & 158 & 47.0 & 194 & 48.5 \\
\hline \multicolumn{7}{|l|}{ Preference for RTE* food } \\
\hline No & 20 & 31.2 & 120 & 35.7 & 140 & 35.0 \\
\hline Yes & 44 & 68.8 & 216 & 64.3 & 260 & 65.0 \\
\hline \multicolumn{7}{|l|}{ Duration of consumption } \\
\hline Less than one year & 15 & 23.4 & 49 & 14.6 & 64 & 16.0 \\
\hline More than or equal to one year & 49 & 76.6 & 287 & 85.4 & 336 & 84.0 \\
\hline \multicolumn{7}{|l|}{ Timing of consumption } \\
\hline Dinner & 9 & 14.1 & 41 & 12.2 & 50 & 12.5 \\
\hline Breakfast/lunch/supper & 55 & 85.9 & 295 & 87.8 & 350 & 87.5 \\
\hline \multicolumn{7}{|l|}{ Free time consumption } \\
\hline No & 25 & 39.1 & 109 & 32.4 & 134 & 33.5 \\
\hline Yes & 39 & 60.9 & 227 & 67.6 & 266 & 66.5 \\
\hline \multicolumn{7}{|l|}{ Habit of storage } \\
\hline No & 23 & 35.9 & 95 & 28.3 & 118 & 29.5 \\
\hline Yes & 41 & 64.1 & 241 & 71.7 & 282 & 70.5 \\
\hline
\end{tabular}

${ }^{*}$ RTE: Ready-to-eat; ${ }^{*}$ More frequently consumed (two to three times per day, once daily, two to four times per week, once per week and one to three times per month); 'Less frequently consumed (less than once per month)

preparation good advertisement, and high income [45]. This study finding suggests that strict regulations should be developed against the over-branding of RTE food. Effective and sustainable health education on problems of unhealthy diet should target working people.
In this study, respondents over 32 years old were three times more likely to be overweight and obese than their counterparts. This may be partly due to the decreasing metabolic rate and lesser physical activity associated with aging. Other possible reasons for overweight and obesity were chronic NCDs such as ischemic heart 
Table 4 Odds ratio (OR) and 95\% confidence interval (Cl) for being overweight and obese BMI $\geq 25 \mathrm{~kg} / \mathrm{m}^{2}$ among sedentary staffs $(N=400)$

\begin{tabular}{|c|c|c|c|c|}
\hline \multirow[t]{2}{*}{ Characteristics } & \multicolumn{2}{|l|}{ Unadjusted } & \multicolumn{2}{|l|}{ Adjusted $^{\text {a) }}$} \\
\hline & OR 95\%Cl & & OR 95\% Cl & \\
\hline \multicolumn{5}{|l|}{ Age (in years) } \\
\hline 32 or younger & 1 & Reference & 1 & Reference \\
\hline Above 32 & 3.51 & $(1.96-6.27)^{* * *}$ & 3.97 & $(1.82-8.69)^{* *}$ \\
\hline \multicolumn{5}{|l|}{ Sex } \\
\hline Male & 1 & Reference & 1 & Reference \\
\hline Female & 0.89 & $(0.42-1.84)$ & 1.99 & $(0.68-5.79)$ \\
\hline \multicolumn{5}{|l|}{ Marital status } \\
\hline Others & 1 & Reference & 1 & Reference \\
\hline Married & 1.91 & $(1.08-3.36)^{*}$ & 1.57 & $(0.76-3.28)$ \\
\hline \multicolumn{5}{|l|}{ Designation } \\
\hline Other rank & 1 & Reference & 1 & Reference \\
\hline Officer and above & 2.81 & $(1.53-5.15)^{* *}$ & 1.51 & $(0.63-3.60)$ \\
\hline \multicolumn{5}{|l|}{ Smoking } \\
\hline No & 1 & Reference & 1 & Reference \\
\hline Yes & 3.57 & $(1.15-11.06)^{*}$ & 5.62 & $(1.06-29.90)^{*}$ \\
\hline \multicolumn{5}{|c|}{ Frequency of RTE food consumption } \\
\hline Less frequently consumed $^{e}$ & 1 & Reference & 1 & Reference \\
\hline More frequently consumed ${ }^{d}$ & 5.69 & $(2.01-16.12)^{* *}$ & 4.78 & $(1.44-15.85)^{* *}$ \\
\hline \multicolumn{5}{|l|}{ Preference of RTE ${ }^{C}$ food } \\
\hline No & 1 & Reference & 1 & Reference \\
\hline Yes & 11.97 & $(3.67-39.06)^{* * *}$ & 8.93 & $(2.54-31.37)^{* *}$ \\
\hline \multicolumn{5}{|l|}{ Timing of consumption } \\
\hline Dinner & 1 & Reference & 1 & Reference \\
\hline Others $^{b}$ & 4.47 & $(1.06-18.95)^{*}$ & 0.26 & $(0.05-1.31)$ \\
\hline \multicolumn{5}{|l|}{ Intensity of physical exercise } \\
\hline Moderate/vigorous & 1 & Reference & 1 & Reference \\
\hline Light & 2.17 & $(1.14-4.12)^{* *}$ & 3.55 & $(1.63-7.73)^{* *}$ \\
\hline \multicolumn{5}{|l|}{ Leisure activity } \\
\hline Non-sedentary & 1 & Reference & 1 & Reference \\
\hline Sedentary & 3.07 & $(1.27-7.39)^{* *}$ & 3.32 & $\left(1 .(22-9.03)^{* *}\right.$ \\
\hline \multicolumn{5}{|l|}{ Medical history of NCDs ${ }^{a}$} \\
\hline No & 1 & Reference & 1 & Re Reference \\
\hline Yes & 4.18 & $(2.30-7.61)^{* * *}$ & 1.99 & (1. $(0.92-4.33)$ \\
\hline
\end{tabular}

${ }^{\mathrm{a} N C D s:}$ non-communicable diseases; ${ }^{\mathrm{b}}$ Others: breakfast, lunch and supper; ${ }^{\mathrm{C}} \mathrm{RTE}$ : ready-to-eat; ${ }^{\mathrm{d}}$ More frequently consumed (two to three times per day, once daily,

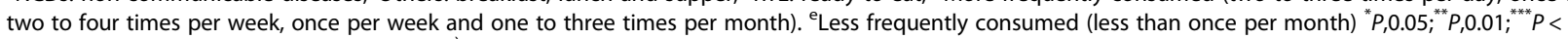
$0.001 ; \mathrm{OR}$ : odds ratio, $\mathrm{Cl}$ : confidence interval ${ }^{\text {a) }}$ Adjusted for the variables listed in this table

diseases, hypertension, and type 2 diabetes mellitus in respondents. This study finding was similar to another study which reported that obesity prevalence was the highest in the adult population [46]. A study from Nepal showed that adults were more likely to be overweight [47]. Healthy lifestyle behavior should be adopted from younger ages to prevent metabolic diseases and obesity in adults.
This study showed that smokers were nearly six times more likely to be overweight and obese than nonsmokers. The relationship between smoking and obesity was not clearly understood [48]. A study from Japan showed that smoking was associated with obesity, but the association depended on the number of cigarettes smoked, not on the duration of smoking. Short-term heavy smokers were more likely to be obese than long- 
term light smokers [49]. This study finding was contrary to another study which found that smoking was negatively associated with overweight and obesity [50]. Nicotine, being a cholinergic agonist, affects eating. Another possible reason is that smoking impaired the taste of the meal and reduced calorie absorption. A study from the United Kingdom mentioned that former smokers were more likely to be obese than current smokers and nonsmokers [51]. In Myanmar, people smoked at smokefree public areas as the Tobacco Control law is not strictly enforced in the country. Therefore, to reduce the risk of NCDs, the Tobacco Control Law in Myanmar should be strictly enforced.

The current study revealed that respondents who did physical exercises were less likely to overweight and obesity. Due to the modern fast-paced living, the nature of the work becomes more sedentary and people become physically inactive. High consumption of energy-dense food such as RTE food has more chance to be physically inactive lives. Sedentary work nature leads to reduced energy expenditure and increased risk of overweight and obesity. The low physical activity was associated with overweight and obesity [52]. This finding is consistent with studies done in Myanmar, Malaysia, and the United States [53-55]. Working environments should promote physical activity and integrating enough public spaces for physical exercise should be considered in urban development and planning.

This study indicated that respondents who had sedentary activities during their leisure time were more likely to be overweight and obese than their counterparts. Low energy expenditure due to sedentary lifestyles increases the risk of overweight and obesity. Sedentary staff would like to spend most of their time sitting, watching TV, using the internet, or playing games. Increased screentime might result in overweight and obesity. One Indonesian study reported a significant positive association between sedentary activities and obesity [56]. A study conducted in India also proved that prolonged sedentary activities are important predictors of obesity [57]. Prolonged screen-time leads to passive snacking and drinking of beverages [58]. Highly sedentary behavior, such as watching television, is frequently associated with an increased risk of obesity [59].

There were some limitations in this study. Firstly, this study was conducted only in Nay Pyi Taw Union Territory, Myanmar. Thus, the findings may not be representative of the whole country. Secondly, the cross-sectional nature of the study could not find out the causal inferences. Thirdly, data collected on risk behaviors such as RTE food consumption, physical activities, sedentary lifestyle, smoking, and alcohol drinking could have subjective or recall bias as they were self-reported data. Fourthly, this study did not measure the central obesity of sedentary staff. Longitudinal studies with more detailed information should be performed in the future. This study is supposed to be the first study to identify the associations between BMI and RTE food consumption among sedentary staff in Myanmar.

\section{Conclusions}

This study pointed out that frequent RTE food consumption and physically inactive lifestyles were the major predictors of overweight and obesity. Age, smoking, and sedentary leisure activities were positively associated with overweight and obesity. Effective and sustainable health promotion focusing on healthy dietary habits and active lifestyles should be implemented at workplaces. Every sedentary worker should be aware of the food-based dietary guidelines of the country. Policymakers should implement an effective and sustainable action plan on the compulsory labeling of nutritional information on the packaging of RTE food. Moreover, over-branding of RTE food should be strictly prohibited. This study highlights the urgent need for an awareness program on RTE food targeting the working community. Furthermore, the study findings suggest the working community to reduce sedentary activities, which in turn, will reduce the burden of obesity. It is strongly recommended that national level policies should be developed on healthy lifestyle promotion especially in workplace settings to become a healthy working community.

\section{Supplementary information}

Supplementary information accompanies this paper at https://doi.org/10. 1186/s12889-020-8308-6.

Additional file 1. English questionnaire.

\section{Abbreviations}

AOR: Adjusted odds ratio; BMI: Body Mass Index; Cl: Confidence Interval; NCDs: Non-communicable diseases; OR: Odds Ratio; RTE food: Ready-to-eat food; SPSS: Statistical Package of Social Science; WHO: World Health

Organization

\begin{abstract}
Acknowledgements
We would to express our sincere gratitude and appreciation to all director general and sedentary staff from respective departments who participated in this study. We also would like to mention our appreciation to staff from Department of Food and Drug Administration, Ministry of Health and Sports, Myanmar for approving and assisting us to collect the data in Nay Pyi Taw Union Territory, Myanmar. Finally, we would like to thank National Nutrition Unit, Department of Public Health, Ministry of Health and Sports for their kind support.
\end{abstract}

\section{Authors' contributions}

TZT, YMS, and NH conceived and designed the study. TZT, ABT, ATZK collected the primary data. TZT, YMS, ABT, HL, KC, HH, SMC, STND and ATZK carried out the statistical analyzes. All authors participated in interpretation of the results. TZT, YMS, TK, NH, and EY prepared the first draft of manuscript. YMS reviewed and edited the manuscript. All authors critically reviewed, revised, and approved the final manuscript. 


\section{Funding}

None.

\section{Availability of data and materials}

The datasets generated during and/or analyzed during the current study are available from the corresponding author on reasonable request.

\section{Ethics approval and consent to participate}

The ethical approval was granted by the Institutional Technical and Ethical Review Board, University of Public Health, Yangon, Myanmar (Letter no. UPHIRB 2018/Research/31 issued on 30th July 2018). The objectives of the study, interview steps and the contents of the study were explained to the respondents. The interviews were conducted only after getting the written informed consent from the respondents before the interview. It was conducted on a voluntary basis and the respondents could deny participating. At every stage of data handling, data were coded and kept anonymous.

\section{Consent for publication}

Not applicable.

\section{Competing interests}

The authors declare that they have no competing interests.

\section{Author details}

${ }^{1}$ Department of Food and Drug Administration, Ministry of Health and Sports, Nay Pyi Taw, Myanmar. ${ }^{2}$ Department of Healthcare Administration, Nagoya University, Graduate School of Medicine, 65 Tsurumai-cho, Showa-ku, Nagoya 466-8550, Japan. ${ }^{3}$ Nagoya University Asian Satellite Campuses Institute, Nagoya, Japan. ${ }^{4}$ Directorate of Medical Service, Nay Pyi Taw, Myanmar. ${ }^{5}$ Department of Preventative and Social Medicine, University of Medicine, Mandalay, Myanmar. ${ }^{6}$ Department of Public Health, Ministry of Health and Sports, Nay Pyi Taw, Myanmar. ${ }^{7}$ Department of Community and Global Health, Graduate School of Medicine, the University of Tokyo, Tokyo, Japan.

Received: 19 July 2019 Accepted: 31 January 2020

Published online: 10 February 2020

\section{References}

1. Majabadi HA, Solhi M, Montazeri A, Shojaeizadeh D, Nejat S, Farahani FK, et al. Factors influencing fast-food consumption among adolescents in Tehran: a qualitative study. Iran Red Crescent Med J. 2016;18(3):e23890. https://doi.org/10.5812/ircmj.23890.

2. Pelletier JE, Laska MN. Balancing healthy meals and busy lives: association between work, school and family responsibilities and perceived time constraints among young adults. J Nutr Educ Behav. 2012;44(6):481-9. https://doi.org/10.1016/j. jneb.2012.04.001.

3. Smith LP, Ng SW, Popkin BM. Trends in US home food preparation and consumption: analysis of national nutrition surveys and time use studies from 1965-1966 to 2007-2008. Nutr J. 2013;12:45. https://doi.org/10.1186/ 1475-2891-12-45.

4. Popkin BM, Adair LS, Ng SW. Now and then: the global nutrition transition: the pandemic of obesity in developing countries. Nutr Rev. 2012;70(1):3-21. https://doi.org/10.1111/j.1753-4887.2011.00456.x.

5. Bowman SA, Vinyard BT. Fast food consumption of U.S. adults: Impact on energy and nutrient intakes and overweight status. J Am Coll Nutr. 2004; 23(2):163-8. https://doi.org/10.1080/07315724.2004.10719357.

6. Schröder H, Fito M, Covas Ml. Association of fast food consumption with energy intake, diet quality, body mass index and the risk of obesity in a representative Mediterranean population. Br J Nutr. 2007;98:1274-80. https://doi.org/10.1017/ S000711450 7781436

7. Duffey KJ, Gordon-Larsen P, Steffen LM, Jacobs DR, Popkin BM. Regular consumption from fast food establishments relative to other restaurants is differentially associated with metabolic outcomes in young adults. J Nutr. 2009;139(11):2113-8. https://doi.org/10.3945/jn.109.109520.

8. Howard S, Adams J, White M. Nutritional content of supermarket ready meals and recipes by television chefs in the United Kingdom: cross sectional study. BMJ. 2012;345:e7607. https://doi.org/10.1136/bmj.e7607.

9. Powell LM, Nguyen BT, Han E. Energy intake from restaurants: demographics and socioeconomics, 2003-2008. Am J Prev Med. 2012;43: 498-504. https://doi.org/10.1016/jamepre.2012.07.041.
10. Zhai FY, Du SF, Wang ZH, Zhang JG, Du WW, Popkin BM. Dynamics of the Chinese diet and the role of urbanicity, 1991-2011. Obes Rev. 2014;15(1):1626. https://doi.org/10.1111/obr.12124.

11. Karimi-Shahanjarini A, Omidvar N, Bazargan M, Rashidian A, Majdzadeh R, Shojaeizadeh D. Iranian female adolescent's views on unhealthy snacks consumption: a qualitative study. Iran J Public Health. 2010;39(3):92-101.

12. Ssewanyana D, Abubakar A, Baar A, Mwangala PN, Newton CR. Perspectives on underlying factors for unhealthy diet and sedentary lifestyle of adolescents at Kenya coastal setting. Front Public Health. 2018;6(11). https:// doi.org/10.3389/fpubh.2018.00011.

13. World Health Organization. Obesity and overweight. 2013. https://www. who.int/mediacentre/factsheets/fs311/en/. Accessed: 21 March 2019.

14. World Health Organization. Overweight and obesity. 2016. https://www. who.int/news-room/fact-sheets/detail/obesity-and-overweight. Accessed: 31 March 2019.

15. World Health Organization. Global health risks: mortality and burden of disease attributable to selected major risks. World Health Organization. 2009. https://apps.who.int/iris/handle/10665/44203. Accessed 31 Mar 2019.

16. World Health Organization. Country profile.2017. http://www.who.int/snmh/ countries/mmr_en.pdf. Accessed: 15 February, 2019.

17. Pi-Sunyer $X$. The medical risk of obesity. Postgrad Med. 2009;121(6):21-33. https://doi.org/10.3810/pgm.2009.11.2074.

18. Tsai AG, Williamson DF, Glick HA. Direct medical cost of overweight and obesity in the USA: a quantitative systematic review. Obes Rev. 2011;12(1): 50-61. https://doi.org/10.1111/j.1467-789X.2009.00708.x.

19. Beaney T, Burrell LM, Castillo RR, Charchar FJ, Cro S, Damasceno A, et al. May measurement month 2018: a pragmatic global screening campaign to raise awareness of blood pressure by the international Society of Hypertension. Eur Heart J. 2019;40(25):2006-17. https://doi.org/10.1093/ eurheartj/ehz300.

20. Rashid AA, Devaraj NK. Oh no! now I have diabetes. RMJ. 2018;43(4):776-8.

21. Chia YC, Ching SM, Chew BN, Devaraj NK, Siti Suhaila MY, Tay CL, et al. May Measurement Month 2017 blood pressure screening: findings from Malaysia-South-East Asia and Australasia. Eur Heart J Suppl. 2019;21(Suppl D):D77-9. https://doi.org/10.1093/eurheartj/suz061

22. Sook LW, Sablihan NI, Ismail S, Devarai NK, Mooi CS. Factors associated with the level of physical activities among non-academic staffs in the Faculty of Medicine and Health Sciences of a public university in Selangor, Malaysia. Mal J Med Health Sci. 2019;15(2):47-55.

23. Angkurawaranon C, Jiraporncharoen W, Chenthanakij B, Doyle P, Nitsch D. Urban environments and obesity in Southeast Asia: A systematic review, Meta-Analysis and Meta-Regression. PLoS One. 2014;9(11):e113547. https:// doi.org/10.1371/ journal.pone.0113547.

24. Ng M, Fleming T, Robinson M, Thomson B, Graetz N, Margono C, et al. Global, regional, and national prevalence of overweight and obesity in children and adults during 1980-2013: a systematic analysis for the global burden of disease study. 2013. Lancet. 2014;384(9945):766-81. https://doi. org/10.1016/S0140/6736(14)60460.8.

25. Helble M, Francisco K. The upcoming obesity crisis in Asia and the Pacific: First cost estimates. In: ADBI working paper 743. Tokyo: Asian Development Bank Institute; 2017. https://www.adb.org/sites/default/files/publication/ 320411/adbi-wp743.pdf. Accessed: 15 December 2018.

26. International Food Policy Research Institute. 2014 Global Nutrition Report. https://globalnutritionreport.org/reports/2014-global-nutrition-report/. Accessed 15 Dec 2018.

27. Hong SA, Peltzer K, Lwin KT, Aung LS. The prevalence of underweight, overweight and obesity and their related socio-demographic and lifestyle factors among adult women in Myanmar, 2015-16. PLoS One. 2018;13(3): 0194454. https://doi.org/10.1371/journal.pone.0194454.

28. World Health Organization. Non-communicable Diseases (NCD) Country Profiles. 2014. https://apps.who.int/iris/bitstream/handle/10665/128038/ 9789241507509_eng.pdf;jsessionid=8999B4F3A66B716B5388DA34B041F85 8? sequence=1. Accessed 24 Mar 2019.

29. Downs SM, Glass S, Linn KK, Fanzo J. The interface between consumers and their food environment in Myanmar: an exploratory mixed-methods study. Public Health Nutr. 2018:1-14. https://doi.org/10.1017/S1368980018003427.

30. Stanton Emms Strategy Consultants. Asia Pacific Food Insight Series 1993 to 2013. Myanmar food and beverages 2018: Strategic directions and scenarios for Myanmar's markets and industry. http://www.foodandbeverage.biz/ images/Myanmar_Food_and_Beverages_2018_Brochure_Web_.pdf. Accessed 15 Apr 2019 
31. Danaei G, Singh GM, Paciorek CJ, Lin JK, Cowan MJ, Finucane MM, et al. The global cardiovascular risk transition: associations of four metabolic risk factors with national income, urbanization, and Western diet in 1980 and 2008. Circulation. 2013;127(14):1493-502. https://doi.org/10.1161/ CIRCULATIONAHA.113.001470.

32. Hancock C, Kingo L, Raynaud O. The private sector, international development and NCDs. Glob Health. 2011;7:23. https://doi.org/10.1186/ 1744-8603-7-23.

33. Ministry of Health and Sports. Non-communicable disease risk factor survey. Myanmar; 2009. https://www.who.int/ncds/surveillance/steps/2009_ STEPS_ Survey_Myanmar.pdf. Accessed: 30 March 2019

34. Ministry of Health and Sports, Republic of Union of Myanmar. National strategic plan for prevention and control of NCDs (2017-2021). Myanmar; 2017. http://www.searo.who.int/entity/ncd_tobacco_surveillance/ monitoring_fw/mmr_ncd_action_plan_2017_2021.pdf. Accessed: 21 February 2019

35. World Health Organization. Global data base for body mass index. 2006 http://www.assessmentpsychology.com/icbmi.htm. Accessed: 22 April 2019.

36. Fleischhacker SE, Evenson KR, Rodriguez DA, Ammerman AS. A systematic review of fast food access studies. Obes Rev. 2011;12(5):e460-71. https://doi. org/10.1111/j.1467-789X.2010.00715.x

37. Niba LL, Atanga MB, Navti LK. A cross sectional analysis of eating habits and weight status of university students in urban Cameroon. BMC Nutr. 2017;3: 55. https://doi.org/10.1186/s40795-017-0178-7.

38. Alkerwi A, Crichton GE, Heber JR. Consumption of ready-made meals and increased risk of obesity: findings from the observation of cardiovascular risk factors in Luxembourg (ORISCAV-LUX) study. Br J Nutr. 2015;113(2):270-7. https://doi.org/10.1017/ S00071145 14003468.

39. Pengpid S, Peltzer K. The prevalence of underweight, overweight/obesity and their related lifestyle factors in Indonesia, 2014-2015. AIMS Public Health. 2017:4(6):633-49. https://doi.org/10.3934/publichealth.2017.6.633.

40. Al-Otaibi HH, Basuny AM. Fast food consumption associated with obesity/ overweight risk among university female student in Saudi Arabia. Pak J Nutr. 2015;14(8):511-6. https://doi.org/10.3923/ pjn. 2015. 511. 516.

41. Jabs J, Devine CM. Time scarcity and food choices: an overview. Appetite. 2006;47(2):196-204. https://doi.org/10.1016/j.appet.2006.02.014.

42. Inglis V, Ball K, Crawford D. Why do women of low socioeconomic status have poorer dietary behaviours than women of higher socioeconomic status? A qualitative exploration. Appetite. 2005;45(3):334-43. https://doi. org/10.1016/ j.appet. 2005.05.003.

43. Harris JL, Bargh JA, Brownell HD. Priming effects of television food advertising on eating bahavior. Health Psychol. 2009;28(4):404-13. https:// doi.org/10.1037/a0014399.

44. Story M, French S. Food advertising and marketing directed at children and adolescents in the US. Int J Behav Nutr Phys Act. 2004;1:3. https://doi.org/10. 1186/1479-5868-1-3.

45. Wang MC, Naidoo N, Ferzacca S, Reddy G, Vandam RM. The role of women in food provision and food choice decision-making in Singapore. A case study. Ecol Food Nutr. 2014;53(6):658-77. https://doi.org/10.1080/03670244. 2014.911178.

46. Thielman J, Harrington D, Rosella LC, Manson H. Prevalence of age-specific and sex specific overweight and obesity in Ontario and Quebec, Canada: a cross-sectional study using direct measures of height and weight. BM. Open. 2018;8:e022029. https://doi.org/10.1136/bmjopen-2018-022029.

47. Rawal LB, Kanda K, Mahumud RA, Joshi D, Mehata S, Shrestha N, et al. Prevalence of underweight, overweight and obesity and their associated risk factors in Nepalese adults: Data from a nationwide survey, 2016. PLoS One. 2018;13(11):0205912. doi: https://doi.org/10.1372/1371/journal.pone. 0205912.

48. Albanes D, Jones YD, Micozzi MS, Mattson ME. Associations between smoking and body weight in the US population: analysis of NHANES II. Am J Public Health. 1987;77(4):439-44. https://doi.org/10.2105/AJPH.77.4.439.

49. Watanabe T, Tsujino I, Konno S, Ito YM, Takashina C, Sato T, et al. Association between smoking status and obesity in a Nationwide survey of Japanese adults. PLoS One. 2016;11(3):e0148926. https://doi.org/10.1371/ journal.pone.0148926.

50. Flegal KM, Troiano RP, Pamuk ER, Kuczmarski RJ, Campbell SM. The influence of smoking cessation on the prevalence of overweight in the United States. N Engl J Med. 1995;333(18):11651170. https://doi.org/10.1056/ NEJM199511023331801.
51. Dare S, Mackay DF, Pell JP. Relationship between smoking and obesity: a cross-sectional study of 499,504 middle-aged adults in the UK general population. PLoS One. 2015;10(4):e0123579. https://doi.org/10.1371/ journal. pone. 0123579

52. Dunton GF, Berrigan D, Ballard-Barbash R, Graubard B, Atienza AA. Joint associations of physical activity and sedentary behaviors with body mass index results from a time use survey of US adults. Int J Obes. 2009;33(12): 1427-36. https://doi.org/10.1038/ijo.2009.174.

53. Htet AS, Bjertness MB, Sherpa LY, Kjøllesdal MK, Oo WM, Meyer HE, et al. Urban-rural differences in the prevalence of non-communicable diseases risk factors among 25-74 years old citizens in Yangon Region, Myanmar: a cross sectional study. BMC Public Health. 2016;16:1225. https://doi.org/10. 1186/s12889-016-3882-3.

54. Chan YY, Lim KK, Lim HK, Teh CH, Kee CC, Cheong SM, et al. Physical activity and overweight/obesity among Malaysian adults: findings from the 2015 National Health and morbidity survey (NHMS). BMC Public Health. 2017;17:733. https://doi.org/10.1186/s12889-017.4772.z.

55. Choi BK, L-Schnall P, Yang H. Set al. Sedentary work, low physical job demand, and obesity in US workers. Am J Ind Med. 2010;53(11):1088-101. https://doi.org/10.1002/1jim.20886.

56. Nurwanti E, Uddin M, Chang JS, Hadi H, Syed-Abdul S, Su EC, et al. Roles of sedentary behaviors and unhealthy foods in increasing the obesity risk in adult men and women: a cross-sectional national study. Nutrients. 2018; 10(6):704. https://doi.org/10.3390/nu10060704.

57. Agrawal P, Gupta K, Mishra V, Agrawal S. Effects of sedentary lifestyle and dietary habits on body mass index change among adult women in India: findings from a follow-up study. Ecol Food Nutr. 2013;52(5):387-406. https:// doi.org/10.1080/ 03670244.2012.19346.

58. Pulsford RM, Stamatakis E, Britton AR, Brunner EJ, Hillsdon MM. Sitting behavior and obesity: evidence from the Whitehall II study. Am J Prev Med. 2013;44(2):132-8. https://doi.org/10.1016/j.amepre.2012.10.009.

59. Ghose B. Frequency of TV viewing and prevalence of overweight and obesity among adult women in Bangladesh: a cross-sectional study. BMJ Open. 2017;7(1):e014399. https://doi.org/10.1136/bmjopen-2016-014399.

\section{Publisher's Note}

Springer Nature remains neutral with regard to jurisdictional claims in published maps and institutional affiliations.

Ready to submit your research? Choose BMC and benefit from:

- fast, convenient online submission

- thorough peer review by experienced researchers in your field

- rapid publication on acceptance

- support for research data, including large and complex data types

- gold Open Access which fosters wider collaboration and increased citations

- maximum visibility for your research: over $100 \mathrm{M}$ website views per year

At $\mathrm{BMC}$, research is always in progress.

Learn more biomedcentral.com/submissions 